\title{
Ubiquitous occurrence of sulfonamides in tropical Asian waters.
}

\begin{abstract}
Seven sulfonamides, trimethoprim, five macrolides, lincomycin and three tetracyclines were measured in 150 water samples of sewage, livestock and aquaculture wastewater, and river and coastal waters, in five tropical Asian countries. The sum of the concentrations of the target antibiotics in sewage and heavily sewage-impacted waters were at sub- to low-ppb levels. The most abundant antibiotic was sulfamethoxazole (SMX), followed by lincomycin and sulfathiazole. The average concentration of SMX in sewage or heavily sewage-impacted waters was $1720 \mathrm{ng} / \mathrm{L}$ in Vietnam (Hanoi, Ho Chi Minh, Can Tho; $\mathrm{n}=15$ ), $802 \mathrm{ng} / \mathrm{L}$ in the Philippines (Manila; $\mathrm{n}=4$ ), $538 \mathrm{ng} / \mathrm{L}$ in India (Kolkata; $\mathrm{n}=4$ ), $282 \mathrm{ng} / \mathrm{L}$ in Indonesia (Jakarta; $\mathrm{n}=10$ ), and $76 \mathrm{ng} / \mathrm{L}$ in Malaysia (Kuala Lumpur; $\mathrm{n}=6$ ). These concentrations were higher than those in Japan, China, Europe, the US and Canada. A predominance of sulfonamides, especially SMX, is notable in these tropical countries. The higher average concentrations, and the predominance of SMX, can be ascribed to the lower cost of the antibiotics. Both the concentration and composition of antibiotics in livestock and aquaculture wastewater varied widely. In many cases, sulfamethazine (SMT), oxytetracycline (OTC), lincomycin, and SMX were predominant in livestock and aquaculture wastewater. Both human and animal antibiotics were widely distributed in the respective receiving waters (i.e., the Mekong River and Manila Bay). SMT/SMX ratios indicate a significant contribution from livestock wastewater to the Mekong River and nearby canals, with an estimated $\sim 10 \%$ of river water SMX derived from such wastewater. Mass flow calculations estimate that 12 tons of SMX is discharged annually from the Mekong River into the South China Sea. Riverine inputs of antibiotics may significantly increase the concentration of such antibiotics in the coastal waters.
\end{abstract}

Keyword: Antibiotics; Sulfamethoxazole; Sulfamethazine; Oxytetracycline; Mekong Delta; Veterinary antibiotics. 